\title{
Arthroplasty information on the internet
}

\author{
QUALITY OR QUANTITY?
}

\section{M.T. Davaris, \\ M. M. Dowsey, \\ S. Bunzli, \\ P. F. Choong}

From St Vincent's

Hospital, Melbourne,

Australia

Correspondence should be sent to

Peter F. Choong; email:

pchoong@unimelb.edu.au

doi: 10.1302/2633-1462.14.BJO 2020-0006

Bone Joint Open 2020;1-4:64-73.

\begin{abstract}
Aims
Total joint replacement (TJR) is a high-cost, high-volume procedure that impacts patients' quality of life. Informed decisions are important for patients facing TJR. The quality of information provided by websites regarding TJR is highly variable. We aimed to measure the quality of TJR information online.
\end{abstract}

\section{Methods}

We identified 10,800 websites using 18 TJR-related keywords (conditions and procedures) across the Australian, French, German and Spanish Google search engines. We used the Health on the Net (HON) toolbar to evaluate the first 150 websites downloaded for every keyword in each language. The quality of information on websites was inspected, accounting for differences by language and tertiles. We also undertook an analysis of English websites to explore types of website providers.

\section{Results}

'Total joint replacement' had the most results returned (150 million websites), and $9 \%$ of websites are HON-accredited. Differences in information quality were seen across search terms $(p<0.001)$ and tertiles $(p<0.001)$, but not between languages $(p=0.226)$. A larger proportion of $\mathrm{HON}$-accredited websites were seen from keywords in the condition and arthroplasty categories. The first tertile contained the highest number of HON-accredited websites for the majority of search terms. Government/educational bodies sponsored the majority of websites.

\section{Conclusion}

Clinicians must consider the shortage of websites providing validated information, with disparities in both number and quality of websites for TJR conditions and procedures. As such, the challenge for clinicians is to lead the design of reliable, accurate and ethical orthopaedic websites online and direct patients to them. This stands to reward both parties greatly.

Cite this article: Bone Joint Open 2020;1-4:64-73.

Keywords: Orthopaedic, Surgery, Arthroplasty, Internet, Patient education, Websites

\section{Introduction}

Patients use the internet for clarifying their understanding of diagnoses. ${ }^{1,2}$ Over $80 \%$ of patients, clinicians, allied health, and invested third parties do this because of the belief that the internet is a reliable, trustworthy and accessible source, ${ }^{3,4}$ and up to $35 \%$ of patients use it to self-diagnose without clinician follow-up. ${ }^{5}$ In addition, over $70 \%$ of adult consumers sought health information on the internet in recent years, and this is predicted to rise. ${ }^{6}$

There is an extensive and unregulated range of medical and procedural information on the internet that can potentially impact peoples' expectations and decision-making. ${ }^{7,8}$ Amid an overwhelming amount of information, the internet can be misleading if patients lack health and e-health literacy skills to find accurate and relevant information. ${ }^{9-11}$ This can be a difficult skillset to acquire for particular subsets of patients, such as non-English speaking patients and the older demographic, who, despite showing increasing internet usage, may lack awareness and general know-how of using technology. $7,12,13$ 
Table I. Evaluation of instruments used to assess quality of information on internet.

\begin{tabular}{|c|c|c|c|}
\hline Instrument & Details & Advantages & Disadvantages \\
\hline HONcode & $\begin{array}{l}\text { Internet toolbar function that } \\
\text { determines HON accreditation status }\end{array}$ & $\begin{array}{l}\text { Free to download and use; } \\
\text { accessible to patients and clinicians; } \\
\text { WHO support }\end{array}$ & $\begin{array}{l}\text { Voluntary subscription fee for websites } \\
\text {; to become HON-accredited; good quality } \\
\text { sites may lack accreditation and not be } \\
\text { trusted }\end{array}$ \\
\hline DISCERN $^{22}$ & $\begin{array}{l}\text { Assesses the quality of information } \\
\text { regarding treatment choices online }\end{array}$ & Free to use & $\begin{array}{l}\text { Time-consuming, complex, requires } \\
\text { manual and subjective assessment of } \\
\text { components }^{23}\end{array}$ \\
\hline $\begin{array}{l}\text { United States Department of Health } \\
\text { and Human Services, ODPHP National } \\
\text { Quality Health Website Survey }{ }^{25}\end{array}$ & $\begin{array}{l}\text { Measures the reliability and usability } \\
\text { of website information }\end{array}$ & $\begin{array}{l}\text { Broad coverage of website } \\
\text { attributes including website } \\
\text { sponsor }\end{array}$ & Subjective and laborious for lay users ${ }^{23,25}$ \\
\hline
\end{tabular}

HON, Health on the Net; WHO, World Health Organization; ODPHP, Office of Disease Prevention and Health Promotion.

Language is known to affect the quality of information $^{14-18}$ and this may impact the reliability of information that is available to patients living in diverse communities or without English-speaking backgrounds. Therefore, assessment of the reliability of information on the internet is merited.

Healthcare professionals, institutions, and industry groups develop websites for commercial advantage. ${ }^{3}$ In contrast, only a small percentage of websites originate from government/educational and non-profit organizations, raising concerns about objectivity, bias, and accuracy of information sources. ${ }^{19}$ There is a need for greater education and easy-to-use tools that can assist patients and clinicians in ascertaining quality information online. ${ }^{16,17}$

Total joint replacement (TJR) is a common and proven intervention for many patients with end-stage osteoarthritis, and is one of the highest volume medical procedures worldwide. ${ }^{20}$ To date, no studies have evaluated online TJR information. Our aim was to quantify the quality of online TJR-related information across several common Western languages, and categorize information by website sponsor.

\section{Methods}

Our methodology has previously been described. ${ }^{16,17,21}$ Reliable health information on the internet can be found using a number of online instruments. ${ }^{22-25} \mathrm{~A}$ consideration of the key characteristics of each of these tools is presented in Table I. ${ }^{15,16,26}$ To analyze a large number of websites, we chose to use the Health on the Net (HON; Chêne-Bourg, Switzerland) tool for its practicality and time-efficiency compared to other tools, which require manual input and tabulation of results. HON is a not-forprofit multilingual (34 languages) accreditation entity endorsed by the World Health Organization. It certifies health websites according to eight key HON principles: ${ }^{15}$ authority, complementarity, privacy, attribution, justifiability, transparency, financial disclosure, and advertising policy. Website owners can apply for HON accreditation, after which an international, independent, qualified accrediting body of the HON team checks the website for any deficiencies of the HON principles that need to be refined, ensuring that $\mathrm{HON}$ accreditation meets high international benchmarking.

We installed the HONcode toolbar, an algorithm encompassing the $\mathrm{HON}$ principles that determines if a website is HON accredited or not. ${ }^{15}$ This toolbar automatically activates as a visual cue for users if a website has HON accreditation. The toolbar is free and simple to install on any personal computer and can be utilized by patients and clinicians to assess website quality. ${ }^{16}$ The HONcode function is a high-calibre instrument as determined by several studies. ${ }^{16,17}$ It offers excellent overall direction for users to assess the reliability and objectivity of a website. ${ }^{27,28}$ Importantly, a number of studies have utilized the HONcode tool to evaluate website quality, with between $7 \%$ and $27 \%$ of websites accredited. ${ }^{19,29-31}$

In this study, we used the Australian, French, German, and Spanish Google search engines for each respective language search. A free-to-use algorithm ${ }^{32}$ was constructed and coded that automatically searched Google by inputting search term, language, and number of items to be returned. This algorithm was able to determine whether a website is HON accredited. A Microsoft Excel spreadsheet with this information was subsequently generated and the data mined for relevant information. Using our constructed algorithm, we performed an internet search of 18 terms between April and September 2019 (Table II) and assessed 10,800 websites for HON accreditation. English medical language has been used for search terms across each of the other languages on their respective Google search engines. The terms searched were: arthritis; osteoarthritis; end-stage arthritis; bone on bone arthritis; total joint replacement; total joint arthroplasty; total hip replacement; total knee replacement; total hip arthroplasty; total knee arthroplasty; anterior hip replacement; posterior hip replacement; unicompartmental 
Table II. Number and percentage of HON-accredited websites.

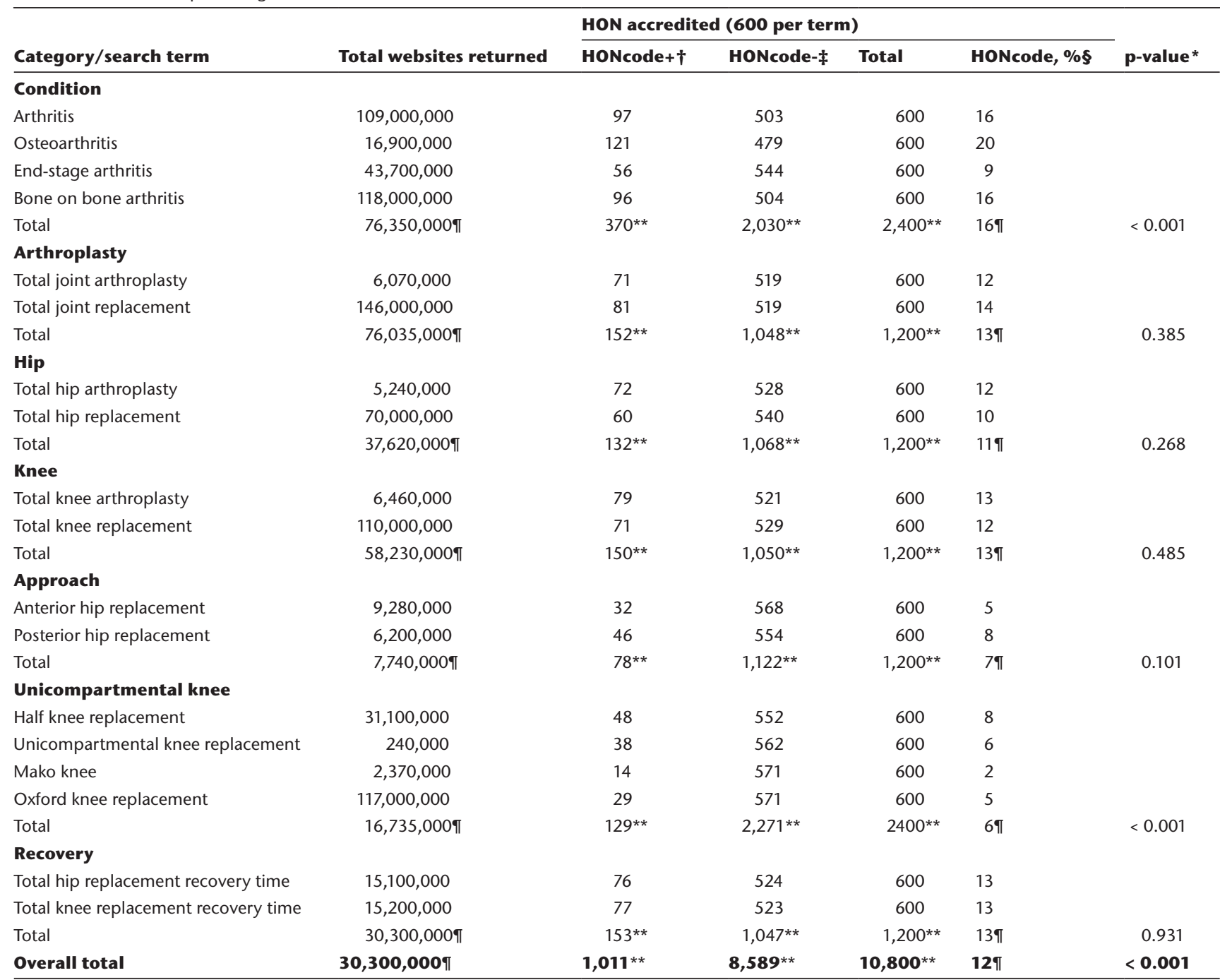

*Pearson chi-squared test, with < 0.05 indicating significant number of $\mathrm{HON}$-accredited websites returned during a search.

$\dagger \mathrm{HON}$-accredited website.

$\ddagger$ Not HON-accredited website.

§Percentage of HON-accredited websites, calculated by HONcode+ divided by the total websites $((\mathrm{HONcode}+)+(\mathrm{HONcode}-))$

TMedian.

**Sum.

knee replacement; half knee replacement; Mako knee; Oxford knee replacement; total hip replacement recovery time; and total knee replacement recovery time. These terms were selected as the most common, relevant, and topical TJR-related terms and procedures used to search for information on the internet. These terms were informed by expert surgeon input (PFC), scanning online patient forums and surveying 15 patients who presented for TJR consultation at a large public hospital in Australia.

HON-accredited website internet search. Patients seldom read websites beyond the first page of results, ${ }^{33}$ so the first 150 websites (approximately 15 pages) returned for each search term from our algorithm were screened for HON accreditation. This was to determine if any reliable online information was potentially being missed by internet users.

Tertile analysis of accredited websites. Additionally, each search term's 150 returned websites were split into tertiles (first 50, middle 50, and last 50), as described in previous studies. ${ }^{19,29,34}$ For each tertile, the percentage of $\mathrm{HON}$-accredited websites were analyzed and compared across languages by a chi-squared test. This was to determine where reliable websites appeared most frequently, namely in the pages most likely (first tertile) to least likely (third tertile).

Quality assurance. For quality control against our constructed algorithm, we manually evaluated all websites of a randomly selected control term, "arthritis", as well as the non-accredited sites using the HON principles to 
Table III. Odds ratio and $95 \%$ confidence limits.

\begin{tabular}{|c|c|c|c|}
\hline Effect on HONcode status & Odds ratio & $95 \%$ confidence interval & p-value* \\
\hline \multicolumn{4}{|l|}{ Search term } \\
\hline Arthritis & 1.00 (referent) & $\mathrm{N} / \mathrm{A}$ & $\mathrm{N} / \mathrm{A}$ \\
\hline Osteoarthritis & 1.310 & 0.975 to 1.759 & 0.073 \\
\hline End-stage arthritis & 0.534 & 0.376 to 0.758 & $<0.001$ \\
\hline Bone on bone arthritis & 0.988 & 0.726 to 1.344 & 0.937 \\
\hline Total joint arthroplasty & 0.696 & 0.501 to 0.968 & 0.031 \\
\hline Total hip arthroplasty & 0.707 & 0.509 to 0.982 & 0.039 \\
\hline Total hip replacement & 0.576 & 0.408 to 0.813 & 0.002 \\
\hline Total knee arthroplasty & 0.786 & 0.570 to 1.084 & 0.142 \\
\hline Total knee replacement & 0.696 & 0.501 to 0.968 & 0.031 \\
\hline Anterior hip replacement & 0.292 & 0.192 to 0.443 & $<0.001$ \\
\hline Posterior hip replacement & 0.431 & 0.297 to 0.624 & $<0.001$ \\
\hline Unicompartmental knee replacement & 0.351 & 0.236 to 0.520 & $<0.001$ \\
\hline Mako knee & 0.123 & 0.070 to 0.220 & $<0.001$ \\
\hline Oxford knee replacement & 0.263 & 0.171 to 0.406 & $<0.001$ \\
\hline Total hip replacement recovery time & 0.752 & 0.543 to 1.040 & 0.085 \\
\hline Total knee replacement recovery time & 0.763 & 0.553 to 1.055 & 0.102 \\
\hline \multicolumn{4}{|l|}{ Tertile } \\
\hline first tertile ( 0 to 50 ) & 1.00 (referent) & $\mathrm{N} / \mathrm{A}$ & $\mathrm{N} / \mathrm{A}$ \\
\hline second tertile (51 to 100 ) & 0.320 & 0.276 to 0.370 & $<0.001$ \\
\hline third tertile (101 to 150$)$ & 0.144 & 0.119 to 0.175 & $<0.001$ \\
\hline \multicolumn{4}{|l|}{ Language } \\
\hline English & 1.00 (referent) & N/A & N/A \\
\hline French & 1.201 & 1.009 to 1.428 & 0.039 \\
\hline German & 1.123 & 0.942 to 1.338 & 0.195 \\
\hline Spanish & 1.119 & 0.939 to 1.333 & 0.211 \\
\hline
\end{tabular}

*Logistic regression, where $<0.05$ indicates likelihood of HON accreditation by search term, tertile, or language to be found in comparison to the reference.

determine if the sites were HON-accredited. This was first to check fidelity of our own constructed algorithm in finding $\mathrm{HON}$-accredited sites against non-accredited sites. Second, by manually evaluating websites with the HON principles in mind, we could also ascertain if a website fulfilled the criteria to be $\mathrm{HON}$-accredited despite not being officially accredited. Previous studies have identified that approximately $5 \%$ of websites are worthy of HON accreditation, but have not yet been accredited, ${ }^{15-17}$ HON accreditation associated variables. Search term, language, and tertile were used as major variables to conduct logistic regression. The reference groups for each variable were arthritis, English, and the first tertile.

Website sponsor analysis. Website sponsorship was determined by MTD reviewing every English website for each English search term. The sponsorship groups were: lawyers; non-profit organizations; government organizations/educational institutions; commercial; orthopaedic specialists and their professional organizations; other healthcare professionals; other (social media, forums, personal websites). Sponsorship is not equivalent to Google advertisements seen on Google results pages (found at the top or sides of searches). As per other similar analyses, these advertisements were not included. ${ }^{16}$
Statistical analysis. Search term, language, and tertile proportion comparisons were performed by chi-squared tests. We conducted two-sided statistical tests, and defined significance as $p<0.05$. We used multiple logistic regression to analyze odds ratios and $95 \%$ confidence intervals for search terms having $\mathrm{HON}$ accreditation with arthritis, English, and the first tertile as the references (Table III). Analyses were performed by Stata v15.0 (StataCorp, College Station, Texas, USA).

Ethics. Quality assurance approval (092/19) was obtained at St Vincent's Hospital Melbourne to question patients about what search terms they would use to find health information regarding their TJR.

\section{Results}

The total number of websites for each TJR-related search term was variable (Table II). 'Total joint replacement' returned the highest number of websites (over 146 million), followed by 'bone on bone arthritis' (approximately 118 million). 'Unicompartmental knee replacement' had the fewest websites, with only 240,000 .

With an overall median of $12 \%$ (interquartile range $5 \%)$, all search terms returned a low percentage of $\mathrm{HON}$-accredited websites (Table II). There were $5 \%$ or 
Table IV. Percentage of HON-accredited websites by language.

\begin{tabular}{|c|c|c|c|c|c|c|c|c|c|c|c|c|c|}
\hline \multirow[b]{2}{*}{ Category/search term } & \multicolumn{3}{|c|}{ English } & \multicolumn{3}{|c|}{ French } & \multicolumn{3}{|c|}{ German } & \multicolumn{3}{|c|}{ Spanish } & \multirow[b]{2}{*}{ p-value * * } \\
\hline & $+^{*}$ & $-\dagger$ & $\% \ddagger$ & $+*$ & $-\dagger$ & $\% \ddagger$ & $+^{*}$ & $-\dagger$ & $\% \ddagger$ & $+{ }^{*}$ & $-\dagger$ & $\% \ddagger$ & \\
\hline \multicolumn{14}{|l|}{ Condition } \\
\hline Osteoarthritis & 25 & 125 & 17 & 33 & 117 & 22 & 32 & 118 & 21 & 31 & 119 & 21 & \\
\hline End-stage arthritis & 13 & 137 & 9 & 16 & 134 & 11 & 13 & 137 & 9 & 14 & 136 & 9 & \\
\hline Bone on bone arthritis & 26 & 124 & 17 & 23 & 127 & 15 & 24 & 126 & 16 & 23 & 127 & 15 & \\
\hline \multicolumn{14}{|l|}{ Arthroplasty } \\
\hline Total joint arthroplasty & 15 & 135 & 10 & 20 & 130 & 13 & 20 & 130 & 13 & 16 & 134 & 11 & \\
\hline Total joint replacement & 21 & 129 & 14 & 21 & 129 & 14 & 17 & 133 & 11 & 22 & 128 & 15 & \\
\hline Total & $36 \S$ & $264 \S$ & $12 \pi$ & $41 \S$ & $259 \S$ & $14 \pi$ & $37 \S$ & $263 \S$ & $12 \pi$ & $38 \S$ & $262 \S$ & $13 \pi$ & 0.668 \\
\hline \multicolumn{14}{|l|}{ Hip } \\
\hline Total hip arthroplasty & 18 & 132 & 12 & 18 & 132 & 12 & 18 & 132 & 12 & 18 & 132 & 12 & \\
\hline Total & $28 \S$ & $272 \S$ & 9 9ा & $36 \S$ & $264 \S$ & $12 \pi$ & $34 \S$ & $266 \S$ & $11 \pi$ & $34 \S$ & $266 \S$ & $11 \pi$ & 0.696 \\
\hline \multicolumn{14}{|l|}{ Knee } \\
\hline Total knee arthroplasty & 14 & 136 & 9 & 22 & 128 & 15 & 22 & 128 & 15 & 21 & 129 & 14 & \\
\hline Total knee replacement & 14 & 136 & 9 & 21 & 129 & 14 & 17 & 133 & 11 & 19 & 131 & 13 & \\
\hline Total & $28^{*}$ & $272 \S$ & 9 9ा & $43 \S$ & $257 \S$ & $14 \pi$ & $39 \S$ & $261 \S$ & $13 \pi$ & $40 \S$ & $260 \S$ & 139 & 0.953 \\
\hline \multicolumn{14}{|l|}{ Approach } \\
\hline Anterior hip replacement & 8 & 142 & 5 & 9 & 141 & 6 & 8 & 142 & 5 & 7 & 143 & 5 & \\
\hline Posterior hip replacement & 10 & 140 & 7 & 13 & 137 & 9 & 12 & 138 & 8 & 11 & 139 & 7 & \\
\hline Total & $18 \S$ & $282 \S$ & $6 \pi$ & $22 \S$ & $278 \S$ & 79 & $20 \S$ & $280 \S$ & $7 \pi$ & $18 \S$ & $282 \S$ & $6 \pi$ & 0.988 \\
\hline \multicolumn{14}{|l|}{ Unicompartmental knee } \\
\hline Half knee replacement & 10 & 140 & 7 & 11 & 139 & 7 & 14 & 136 & 9 & 13 & 137 & 9 & \\
\hline Unicompartmental knee replacement & 11 & 139 & 7 & 9 & 141 & 6 & 9 & 141 & 6 & 9 & 141 & 6 & \\
\hline Mako knee & 5 & 145 & 3 & 3 & 147 & 2 & 4 & 146 & 3 & 2 & 148 & 1 & \\
\hline Oxford knee replacement & 7 & 143 & 5 & 8 & 142 & 5 & 7 & 143 & 5 & 7 & 143 & 5 & \\
\hline \multicolumn{14}{|l|}{ Recovery } \\
\hline Total hip replacement recovery time & 18 & 132 & 12 & 19 & 131 & 13 & 20 & 130 & 13 & 19 & 131 & 13 & \\
\hline Total knee replacement recovery time & 20 & 130 & 13 & 19 & 131 & 13 & 19 & 131 & 13 & 19 & 131 & 13 & \\
\hline Total & $38 \S$ & $162 \S$ & $13 \pi$ & $38 \S$ & $162 \S$ & $13 \pi$ & $39 \S$ & $161 \S$ & $13 \pi$ & $38 \S$ & $162 \S$ & 139 & 0.989 \\
\hline Overall total & $315 \S$ & $2,335 \S$ & 9ף & $312 \S$ & $2,288 \S$ & $13 \pi$ & $294 \S$ & $2,306 \S$ & $11 \pi$ & $293 \S$ & $2,307 \S$ & $12 \pi$ & 0.226 \\
\hline
\end{tabular}

*HON-accredited website.

$\dagger$ Not HON-accredited website.

$\ddagger$ Percentage of $\mathrm{HON}$-accredited websites, calculated by HONcode+ divided by the total websites $((\mathrm{HONcode}+)+(\mathrm{HONcode}-))$.

$\S$ Sum.

TMedian.

**Pearson chi-squaredtest, with $<0.05$ indicating significant number of $\mathrm{HON}$-accreditedwebsites returned during a search.

fewer HON-accredited sites for search terms 'anterior hip replacement', 'Oxford knee replacement', and 'Mako knee' (Table II).

HON-accredited websites were a similar proportion between languages (Table IV, Figure 1), namely French (13\%), Spanish (12\%), German (11\%), and English (9\%). The first tertile (first 50 websites) had the largest percentage of $\mathrm{HON}$-accredited websites (Table V, Figure 2).

Quality assurance. The manual assessment of websites matched the results of our algorithm, confirming its fidelity. For the first 150 "arthritis" (English) results, 20 websites were $\mathrm{HON}$-accredited and 130 were not. We found that $9(9 / 150 ; 6 \%)$ of those non-accredited sites could potentially be $\mathrm{HON}$-accredited when assessed manually.
HON accreditation associated variables. Logistic regression analysis demonstrated that there were significant differences between search terms being $\mathrm{HON}$-accredited (Table III). For language, an accredited site was more likely to be found in French than in English, German or Spanish, which were equally likely to return $\mathrm{HON}$-accredited websites. For tertiles, the second tertile was more likely than the third tertile to have HON-accredited sites.

Website sponsor analysis. Sponsorship analysis of the 150 English websites (Table VI) indicated that the most frequent sponsors were government/education (39\%), followed by orthopaedic specialists/professional organizations (26\%), commercial (18\%), other' (7\%), non-profit (6\%), and other healthcare professionals (3\%). 'Lawyer' sponsored far less sites (< 1\%). 


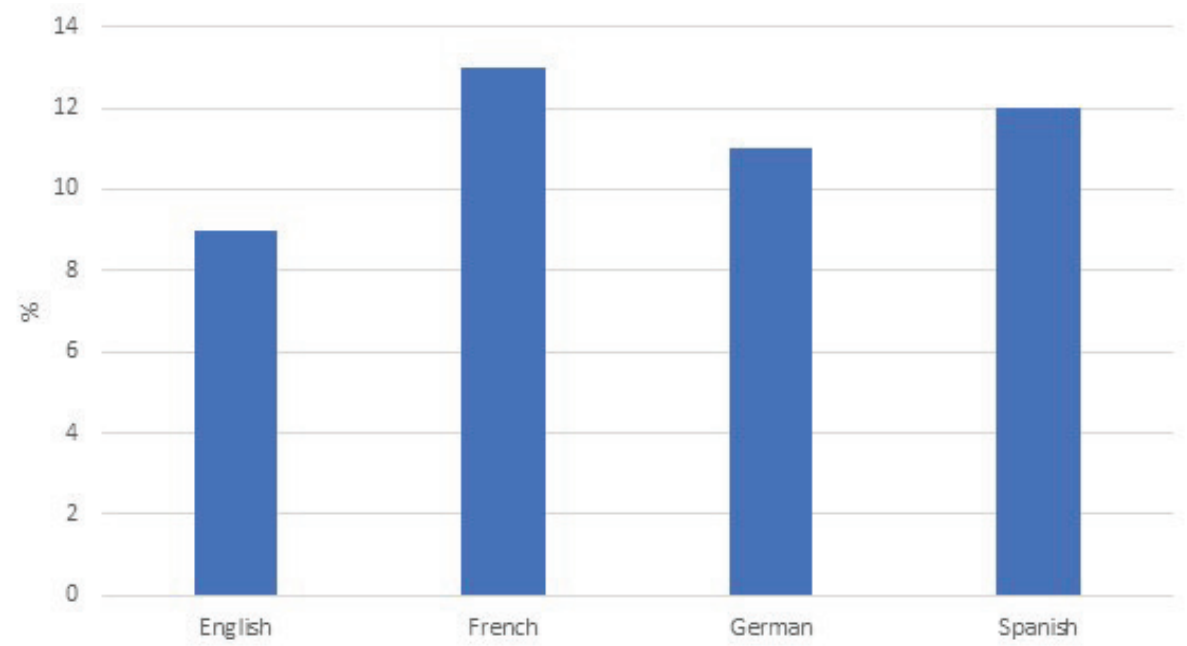

Fig. 1

Column graph of median percentage of HON-accredited sites for all keywords arranged according to language. Each keyword was searched on native Google search engine of respective countries.

Table V. Percentage of HON-accredited websites by tertile.

\begin{tabular}{|c|c|c|c|c|c|c|c|c|c|c|}
\hline \multirow[b]{3}{*}{ Category/search term } & \multicolumn{10}{|c|}{ HON-accredited websites } \\
\hline & \multicolumn{3}{|c|}{ Tertile 1 (sites 1 to 50 ) } & \multicolumn{3}{|c|}{ Tertile 2 (sites 51 to 100) } & \multicolumn{3}{|c|}{ Tertile 3 (sites 101 to 150 ) } & \multirow[b]{2}{*}{ p-value * } \\
\hline & $+\dagger$ & $-\ddagger$ & $\% \S$ & $+\dagger$ & $-\ddagger$ & $\% \S$ & $+\dagger$ & $-\ddagger$ & $\% \S$ & \\
\hline \multicolumn{11}{|l|}{ Condition } \\
\hline Arthritis & 56 & 144 & 28 & 36 & 163 & 18 & 5 & 196 & 3 & $<0.001$ \\
\hline Osteoarthritis & 59 & 141 & 30 & 31 & 169 & 16 & 6 & 194 & 3 & $<0.001$ \\
\hline End-stage arthritis & 36 & 164 & 18 & 11 & 189 & 6 & 9 & 191 & 5 & $<0.001$ \\
\hline Bone on bone arthritis & 70 & 130 & 35 & 29 & 171 & 15 & 22 & 178 & 11 & $<0.001$ \\
\hline \multicolumn{11}{|l|}{ Arthroplasty } \\
\hline Total joint arthroplasty & 43 & 157 & 22 & 24 & 176 & 12 & 4 & 196 & 2 & $<0.001$ \\
\hline Total joint replacement & 55 & 145 & 28 & 17 & 183 & 9 & 9 & 191 & 5 & $<0.001$ \\
\hline \multicolumn{11}{|l|}{ Hip } \\
\hline Total hip arthroplasty & 53 & 147 & 27 & 13 & 187 & 7 & 6 & 194 & 3 & $<0.001$ \\
\hline Total hip replacement & 44 & 156 & 22 & 11 & 189 & 6 & 5 & 195 & 3 & $<0.001$ \\
\hline Total knee arthroplasty & 54 & 146 & 27 & 14 & 186 & 7 & 11 & 189 & 6 & $<0.001$ \\
\hline Total knee replacement & 54 & 146 & 27 & 10 & 190 & 5 & 7 & 193 & 4 & $<0.001$ \\
\hline \multicolumn{11}{|l|}{ Approach } \\
\hline Anterior hip replacement & 21 & 179 & 11 & 5 & 195 & 3 & 6 & 194 & 3 & $<0.001$ \\
\hline Posterior hip replacement & 24 & 176 & 12 & 18 & 182 & 9 & 4 & 196 & 2 & 0.001 \\
\hline \multicolumn{11}{|l|}{ Unicompartmental knee } \\
\hline Half knee replacement & 21 & 179 & 11 & 5 & 195 & 3 & 22 & 178 & 11 & 0.002 \\
\hline Unicompartmental knee replacement & 5 & 195 & 3 & 8 & 192 & 4 & 1 & 199 & 1 & $<0.001$ \\
\hline Mako knee & 16 & 184 & 8 & 10 & 190 & 5 & 3 & 197 & 2 & 0.067 \\
\hline Oxford knee replacement & 23 & 177 & 12 & 15 & 185 & 8 & 0 & 200 & 0 & 0.010 \\
\hline \multicolumn{11}{|l|}{ Recovery } \\
\hline Total hip replacement recovery time & 62 & 138 & 31 & 13 & 187 & 7 & 1 & 199 & 1 & $<0.001$ \\
\hline Total knee replacement recovery time & 56 & 144 & 28 & 10 & 190 & 5 & 11 & 189 & 6 & $<0.001$ \\
\hline
\end{tabular}

*Pearson chi-squared test, with < 0.05 indicating significant number of $\mathrm{HON}$-accredited websites returned during a search.

†HON-accredited website.

$\ddagger$ Not HON-accredited website.

§Percentage of HON-accredited websites, calculated by HONcode+ divided by the total websites (HONcode+) $+(\mathrm{HONcode-}))$.

ISum.

**Median. 


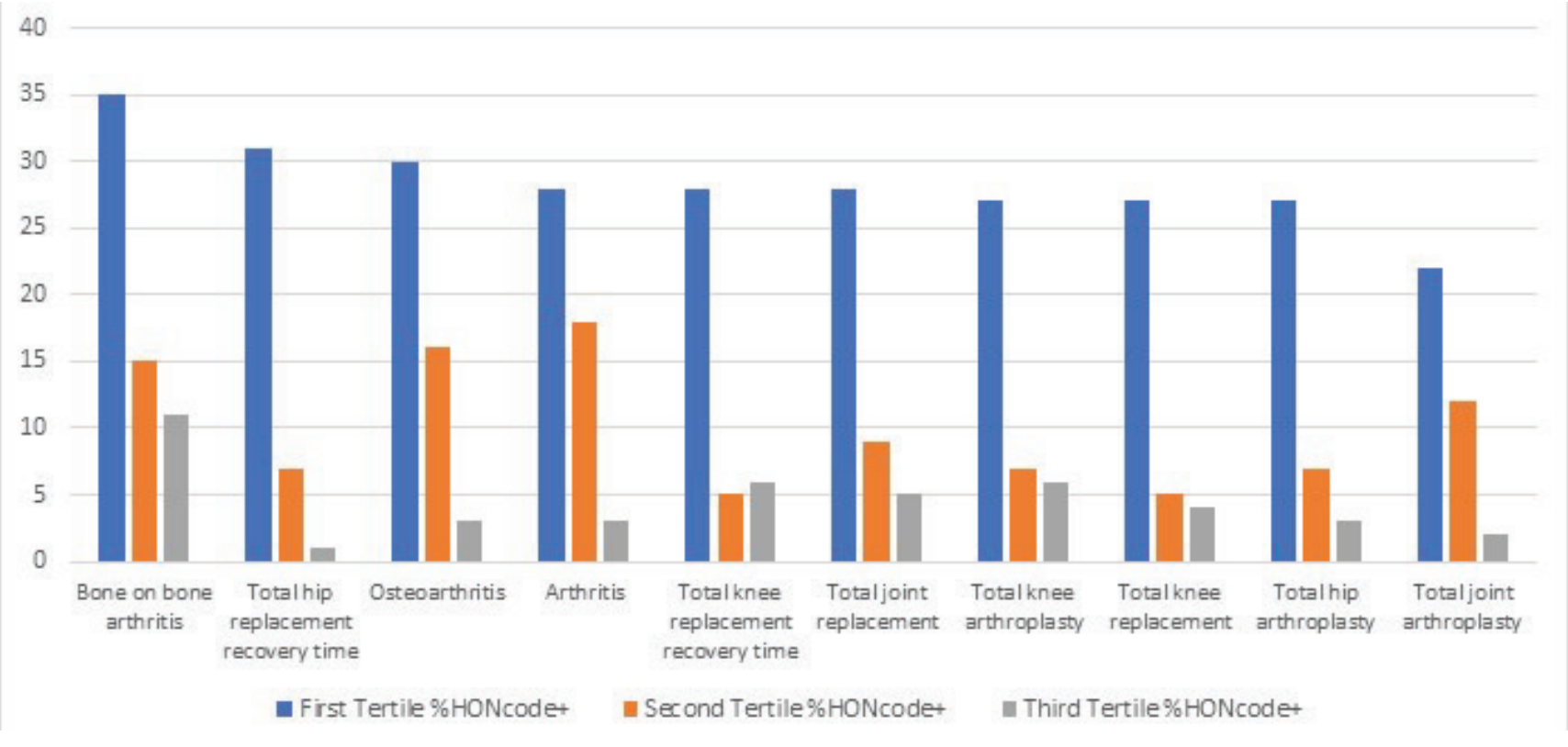

Fig. 2

Clustered column graph of percentage of HON-accredited websites for keywords arranged by tertiles.

Search terms with larger percentages of government/ education also had a larger $\mathrm{HON}$-accredited website percentage. These were the 'condition' (arthritis, osteoarthritis, end-stage arthritis, bone on bone arthritis), 'hip' (total hip arthroplasty, total hip replacement), and 'knee' (total knee arthroplasty, total knee replacement) categories $(p<0.001)$.

\section{Discussion}

This study aimed to quantify the quality of TJR-related online information. We found a substantial variation in the quality of websites returned per search term. As determined by our constructed algorithm, the percentage of website HON accreditation was low for all keywords. There were essentially no differences in $\mathrm{HON}$-accredited websites by language. The first tertile contained the majority of HON-accredited websites most frequently. Governmental or educational institutes sponsored almost $50 \%$ of websites, while nearly a third of websites were led by orthopaedic specialists or professional organizations. Importantly, nearly a fifth of them were commercially sponsored websites.

Generally, trustworthy resources distributing health information are scarce, and websites with accurate TJRrelated information are no exception. Search terms within the categories of condition and arthroplasty only had $16 \%$ and $13 \%$ of $\mathrm{HON}$-accredited websites, respectively. This is less than websites supporting information for urology or surgical oncology conditions, ${ }^{19,29}$ but more than others e.g. gynaecological oncology (15\%), ${ }^{31}$ penile cancer (10.4\%), ${ }^{35}$ and benign prostate hyperplasia (9\%). ${ }^{30}$ In the latter study, ${ }^{30} 7 \%$ of websites were
HON-accredited for the category of 'surgical treatments', similar to our category of 'approach', which also had 7\% of HON-accredited websites. This reflects our hypothesis that reliable, accurate TJR and other online health information is lacking.

These results suggest that patients will encounter poor quality information about arthritis conditions and arthroplasty procedures. As both patients and clinicians may struggle to assess website quality, distrust of orthopaedic internet resources may occur. Worse still, poor information may lead to poor decision-making. A number of previous studies demonstrate poor quality website information across different languages. $15,16,18$ In our study, the percentage of $\mathrm{HON}$-accredited websites were comparable between English (9\%) and French, German and Spanish searches ( $11 \%$ to $13 \%)$. Similar to thoracic surgery, ${ }^{36}$ there is less variation of TJR information between languages than results from earlier studies, ${ }^{19}$ albeit still poor. There is clearly a dearth of reliable online information on TJR, transcending country, and language.

There is a clear propensity for the first 50 websites to contain the majority of $\mathrm{HON}$-accredited websites than the second or third 50. However, despite patients seldom searching further than the first ten results, ${ }^{16}$ patients may still not find the reliable information they need. Commercial interests may explain this pattern, with websites made more prominent to search engines for a premium cost through marketing techniques like pay-per-click advertising. Furthermore, different search platforms may influence the type of websites and information returned. Depending on whether Google or a similar search engine, such as Bing or DuckDuckGo, is used, websites 


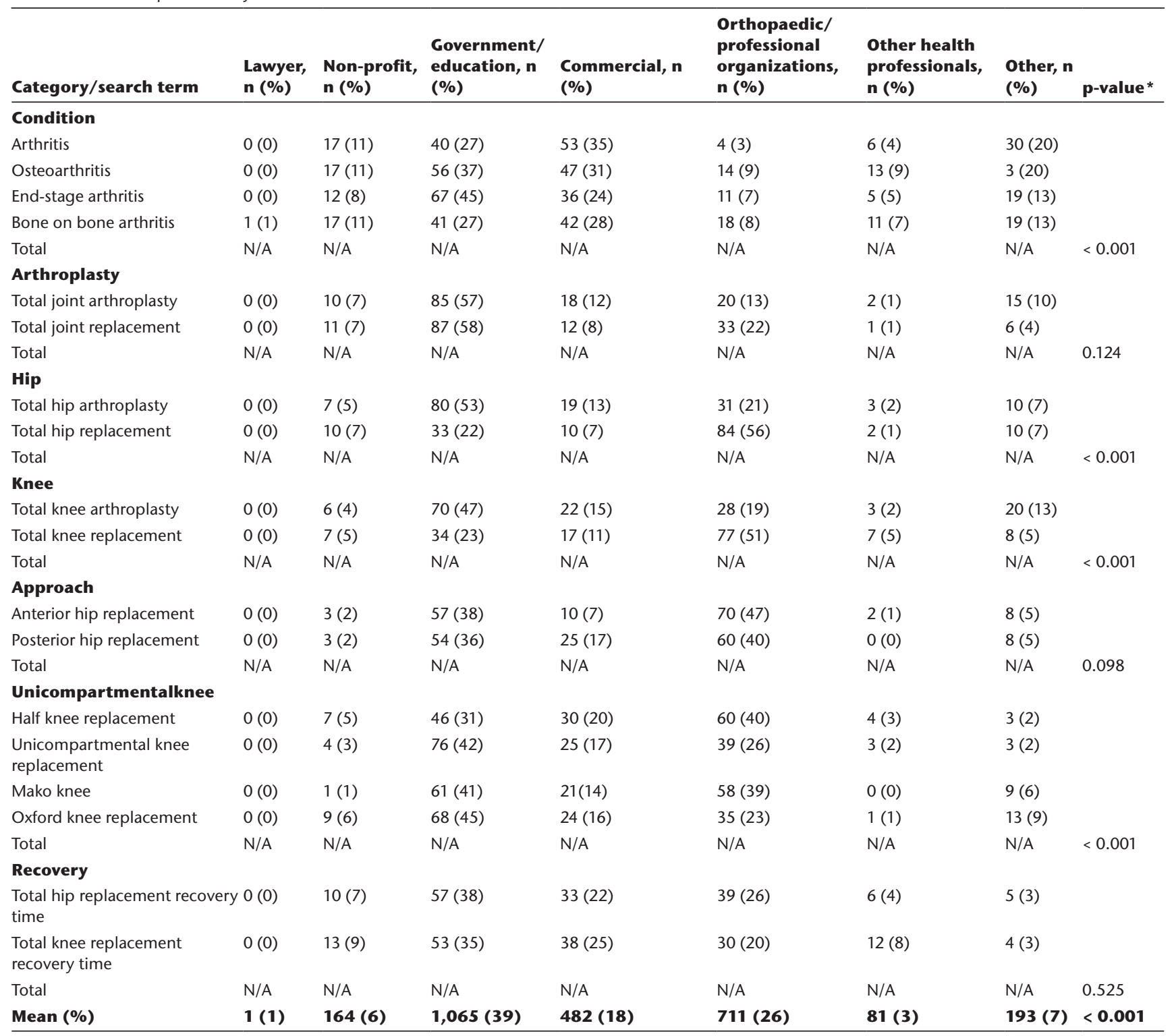

N/A, not applicable.

*Pearson chi-squared test, where $<0.05$ indicates significant difference in number of website sponsors.

may appear in different orders, or not at all. A future study could explore if identical websites appear on the first page of different search engines.

In the digital information era, commercial and marketing initiatives are influencing health information exponentially, which may compromise their impartial insights. ${ }^{37}$ The majority of sponsors in this study comprised government/education or Orthopaedic surgeons/professional organisations. However, almost one in three websites with commercial sponsors suggests that TJR websites may be more influenced by marketing forces, as compared to previously analyzed medical

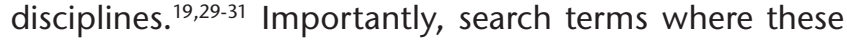
commercial sponsors were more apparent also contained a larger proportion of $\mathrm{HON}$-accredited websites. This may indicate that more objective groups are striving to produce more accurate TJR-related information for the public.

Limitations. Despite HONcode being practical, accessible and validated, several limitations need to be considered. There may be websites with truly reliable information that do not fulfil HONcode criteria, and vice-versa. For example, The Australian Government's Repatriation Medical Authority or the Australian Clinical Practice Guidelines are not HON-accredited, nor is Scotland's National Health Service website, nor several leading American university hospitals. These websites appeared numerous times in our search. It is possible these websites are accredited by 
other tools (Table I). Since 2015, HONcode accreditation is a paid service for which website owners voluntarily apply to have their website $\mathrm{HON}$-accredited. Like previous studies, manual assessment showed that $6 \%$ of websites from our control term ("arthritis") could have HON accreditation. ${ }^{19,29-31}$ Thus, flaws of HONcode may include voluntary application and relative unawareness from patients and clinicians.

Moreover, search engines like Google also utilize geographical features that only allow local search results to be returned. This may be problematic for non-techsavvy patients wanting to learn more about their condition if their city or country does not support the most reliable and recent health information. Research has also shown how social media and health-related YouTube videos influence healthcare. ${ }^{38}$ Patients must heed caution when consuming health information from these largely unregulated media. Hence, concurrently upskilling patient eHealth literacy ${ }^{9}$ may be crucial for patients searching the internet successfully.

Implications. Health websites facilitate patients' understanding of their medical issues. ${ }^{39}$ As such, an opportunity exists to develop and utilize accessible and reliable digital health information tools that support patients when required. ${ }^{40}$ Clinicians should encourage patients to download quality assessment tools like HONcode or could use these themselves to identify and direct patients to reliable websites. This may enhance patientclinician rapport, ${ }^{41}$ informed consent, decision making, and help patients address sensitive health complaints (e.g. urology, gynaecology, and penile cancers) $)^{19,20,35,42}$ In an increasingly digital world with an ageing population, healthcare professionals may serve a critical role in helping to direct patients to the most reliable resources and tools, thereby reducing both patient and their own burden. ${ }^{2}$

Clinicians should consider the shortage of reliable TJRrelated information on the internet across search terms, language and tertiles. Awareness of this poor quality is essential for clinicians to educate and empower patients to conduct thorough health research to obtain superior health literacy. Clinicians can take the initiative to identify and guide patients to reliable and true information on websites.

\section{Twitter}

Follow M. T. Davaris @DavarisMyles

Follow M. M. Dowsey @OPUS_TJR

\section{References}

1. Hesse BW, Greenberg AJ, Rutten LJF. The role of Internet resources in clinical oncology: promises and challenges. Nat Rev Clin Oncol. 2016;13(12):767-776.

2. Hungerford DS. Internet access produces misinformed patients: managing the confusion. Orthopedics. 2009;32(9):658-.

3. Risk A, Dzenowagis J. Review of Internet health information quality initiatives. J Med Internet Res. 2001;3(4):E28.
4. Couper MP, Singer E, Levin CA, et al. Use of the Internet and ratings of information sources for medical decisions: results from the decisions survey. Med Decis Making. 2010;30(5 Suppl):106-114

5. Fox S, Pew DM. Internet and American life project. 2020. https://www.pewresearch. org/internet/2013/01/15/health-online-2013/ (date last accessed 05 March 2020).

6. Nagler RH, Gray SW, Romantan A, et al. Differences in information seeking among breast, prostate, and colorectal cancer patients: results from a populationbased survey. Patient Educ Couns. 2010;81(suppl):S54-S62.

7. Berland GK, Elliott MN, Morales LS, et al. Health information on the Internet: accessibility, quality, and readability in English and Spanish. JAMA. 2001;285(20):2612-2621.

8. Bruce JG, Tucholka JL, Steffens NM, Neuman HB. Quality of online information to support patient decision-making in breast cancer surgery. J Surg Oncol. 2015;112(6):575-580.

9. Norman CD, Skinner HA. eHealth literacy: essential skills for consumer health in a networked world. J Med Internet Res. 2006;8(2):e9.

10. Norman CD, Skinner HA. eHEALS: the eHealth literacy scale. J Med Internet Res. 2006;8(4):e27.

11. Del Giudice $\mathbf{P}$, Bravo G, Poletto $\mathbf{M}$, et al. Correlation between eHealth literacy and health literacy using the eHealth literacy scale and real-life experiences in the health sector as a proxy measure of functional health literacy: cross-sectional webbased survey. J Med Internet Res. 2018;20(10):e281.

12. Arcury TA, Sandberg JC, Melius KP, et al. Older adult Internet use and eHealth literacy. Journal of applied gerontology: the official journal of the Southern Gerontological Society. 2018;733464818807468

13. Mueller J, Jay C, Harper S, et al. Web use for symptom appraisal of physica health conditions: a systematic review. J Med Internet Res. 2017;19(6):e202.

14. Chen X, Siu LL. Impact of the media and the Internet on oncology: survey of cancer patients and oncologists in Canada. J Clin Oncol. 2001;19(23):4291-4297.

15. Foundation HOtN. The HON code of conduct for medical and health web sites. HON Foundation Ginebra. 2009. https://www.hon.ch/HONcode/ (date last accessed 05 March 2020).

16. Eysenbach G, Köhler C. How do consumers search for and appraise health information on the world wide web? qualitative study using focus groups, usability tests, and in-depth interviews. BMJ. 2002;324(7337):573-577.

17. Gaudinat A, Grabar N, Boyer C. Machine learning approach for automatic quality criteria detection of health web Pages. Stud Health Technol Inform. 2007;129/Pt 1):705-709.

18. Eastham JA. Robotic-Assisted prostatectomy: is there truth in advertising? Eur Urol. 2008;54(4):720-722

19. Lawrentschuk N, Abouassaly R, Hackett N, Groll R, Fleshner NE. Health information quality on the Internet in urological oncology: a multilingual longitudinal evaluation. Urology. 2009;74(5):1058-1063.

20. Graves S, Davidson D, de Steiger R, Tomkins A. Australian orthopaedic association national joint replacement registry annual report. Australian Orthopaedic Association National Joint Replacement Registry. 2014

21. Ekman A Hall $\mathbf{P}$, Litton J-E. Can we trust cancer information on the Internet?--A comparison of interactive cancer risk sites. Cancer Causes Control. 2005;16(6):765-772

22. Charnock D, Shepperd S. Learning to discern online: applying an appraisal tool to health websites in a workshop setting. Health Educ Res. 2004;19(4):440-446.

23. Dobbins $\mathbf{M}$, Watson $\mathbf{S}$, Read $\mathbf{K}$, et al. A tool that assesses the evidence, transparency, and usability of online health information: development and reliability assessment. JMIR Aging. 2018;1(1):e3

24. Ltd M. The LIDA instrument. UK: Minervation Ltd Oxford, 2007. http://www. minervation.com/wp-content/uploads/2011/04/Minervation-LIDA-instrument-v1-2 pdf

25. Devine T, Broderick J, Harris LM, Wu H, Hilfiker SW. Making quality health websites a national public health priority: toward quality Standards. J Med Internet Res. 2016;18(8):e211.

26. Avery KNL, Blazeby JM, Lane JA, et al. Decision-Making about PSA testing and prostate biopsies: a qualitative study embedded in a primary care randomised trial. Eur Urol. 2008;53(6):1186-1193.

27. Smith $\mathbf{R P}$, Devine $\mathbf{P}$, Jones $\mathbf{H}$, et al. Internet use by patients with prostate cancer undergoing radiotherapy. Urology. 2003;62(2):273-277.

28. Boyer C, Baujard V, Griesser V, Scherrer JR. HONselect: a multilingual and intelligent search tool integrating heterogeneous web resources. Int J Med Inform. 2001:64(2-3):253-258

29. Lawrentschuk N, Sasges D, Tasevski R, et al. Oncology health information quality on the Internet: a multilingual evaluation. Ann Surg Oncol. 2012;19(3):706-713. 
30. Chen EC, Manecksha RP, Abouassaly R, et al. A multilingual evaluation of current health information on the Internet for the treatments of benign prostatic hyperplasia. Prostate Int. 2014;2(4):161-168.

31. Hewitt E, Mulcahy A, Lawrentschuk $\mathbf{N}$, et al. Health information quality on the Internet in gynaecological oncology: a multilingual evaluation. International journal of gynecological cancer. 2014. Lippincott Williams \& Wilkins.

32. Gargalionis J. Honcoder: a Python 3 interface to the HONcode website certification database [Github]. 2019. https://github.com/johngarg/honcoder (date last accessed 05 March 2020).

33. Killeen S, Hennessey A, El Hassan Y, et al. Gastric cancer-related information on the Internet: incomplete, poorly accessible, and overly commercial. Am J Surg. 2011;201(2):171-178.

34. Alkhateeb S, Lawrentschuk $\mathbf{N}$. Consumerism and its impact on robotic-assisted radical prostatectomy. BJU Int. 2011;108(11):1874-1878.

35. Teh J, Op't Hoog S, Nzenza T, et al. Penile cancer information on the Internet: a needle in a haystack. BJU Int. 2018;122 Suppl 5(suppl 5):22-26.

36. Davaris M, Barnett S, Abouassaly R, Lawrentschuk N. Thoracic surgery information on the Internet: a multilingual quality assessment. Interact $J$ Med Res. 2017;6(1):e5.

37. Mayer MA, Karkaletsis V, Stamatakis K. MedlEQ-quality labelling of medical web content using multilingual. Medical and Care Compunetics 3. 2006:121-183.

38. Gabarron E, Fernandez-Luque L, Armayones M, Lau AY. Identifying measures used for assessing quality of YouTube videos with patient health information: a review of current literature. Interact J Med Res. 2013;2(1):e6.

39. Hoppe IC. Readability of patient information regarding breast cancer prevention from the web site of the National cancer Institute. J Cancer Educ. 2010;25(4):490-492.

40. Cassidy JT, Baker JF. Orthopaedic patient information on the world wide web: an essential review. J Bone Joint Surg Am. 2016;98(4):325-338.

41. Sechrest RC. The Internet and the physician-patient relationship. Clin Orthop Relat Res. 2010;468(10):2566-2571.

42. Lawrentschuk N, Sasges D, Tasevski R, et al. Oncology health information quality on the Internet: a multilingual evaluation. Ann Surg Oncol. 2012;19(3):706-713.
Author information:

M. T. Davaris, BBiomed, MD, PhD Candidate, Medical Docto

M. M. Dowsey, BHealthSci (Nursing), MEpi, PhD, Associate Professor of Research

S. Bunzli, BPhty, PhD, Physiotherapist, Research Associate

S. Bunzli, BPhty, PhD, Physiotherapist,
P. F. Choong, MBBS, MD, FRACS, FAOA

Department of Surgery, St Vincent's Hospital, University of Melbourne, Melbourne, Australia.

Author contributions:

M. T. Davaris: Set up the project, Collected and analyzed data, Wrote and edited the manuscript.

- M. M. Dowsey: Set up the project, Analyzed the data, Wrote and edited the manuscript.

S. Bunzli: Set up the project, Wrote and edited the manuscript.

P. F. Choong: Set up the project, Wrote and edited the manuscript.

Funding statement:

No benefits in any form have been received or will be received from a commercial party related directly or indirectly to the subject of this article.

\section{ICMJE COI statement:}

- P. Choong declares personal fees paid by Stryker Orthopaedics. Depuy Johnson \& Johnson, Ziimer, and Kluwer, and grants paid by Medacta and Depuy. M. Dowsey declares grants paid by Medacta, National Health \& Medical Research Council, Australian Research Council, and Pfizer.

Acknowledgements:

M. Davaris is supported through the National Health and Medical Research Council (NHMRC) Centre of Research Excellence in Total loint Replacement (APP1116325) at the Department of Surgery, St Vincent's Hospital: M. Dowsey holds a NHMRC at the Department of Surgery, St Vincent's Hospital. M. Dowsey holds a NHMRC Career Development Fellowship (APP1122526) and University of Melbourne Dame Kate Camp3). (APP1154203). We thank John Gargalionis for creating the algorithm to collect HONcode data and A/Prof Nathan Lawrentschuk for his previous work that inspired this study.

Ethical review statement:

Quality assurance approval (092/19) was obtained at St Vincent's Hospital, Melbourne.

(c) 2020 Author(s) et al. This is an open-access article distributed under the terms of the Creative Commons Attributions licence (CC-BY-NC-ND), which permits unrestricted use, distribution, and reproduction in any medium, but not for commercial gain, prouse, distribution, and reproduction in any medium, 


\section{University Library}

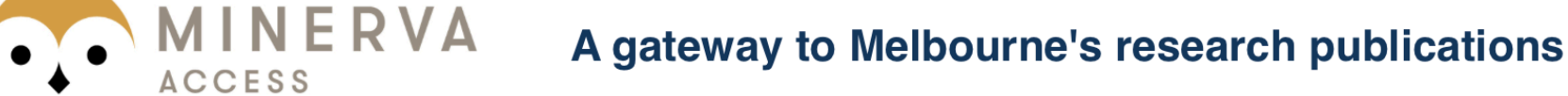

Minerva Access is the Institutional Repository of The University of Melbourne

\section{Author/s:}

Davaris, MT;Dowsey, MM;Bunzli, S;Choong, PF

Title:

Arthroplasty information on the internet: quality or quantity?

Date:

2020-04

Citation:

Davaris, M. T., Dowsey, M. M., Bunzli, S. \& Choong, P. F. (2020). Arthroplasty information on the internet: quality or quantity?. Bone \& Joint Open, 1 (4), pp.64-73. https:// doi.org/10.1302/2633-1462.14.BJO-2020-0006.

Persistent Link:

http://hdl.handle.net/11343/252673

License:

CC BY-NC-ND 